\title{
Thermogravimetric analysis in the study of solid fuels
}

\author{
Robert Wróblewski ${ }^{1}$ and Bartosz Ceran ${ }^{1}$ \\ ${ }^{1}$ Institute of Electrical Power Engineering, Poznan University of Technology, Poznan, Poland
}

\begin{abstract}
Depletion of fossil energy is the reason for the exploration of the possibility of the use of renewable energy resources. In the article describes a method of thermo-gravimetric analysis and concept, design and execution of the instrument to thermogravimetric measurements placed in the Laboratory of Fuel and Energy Conversion of Institute of Electrical Power Engineering of Poznan University of Technology. The further part of the paper contains the results of the tests carried out on two types of solid fuels (pellets from sawdust and energy willow wood chips ) in the form of a thermogravimetric curves. This analysis is to determine the level of the pyrolysis process temperature and degree of conversion of solid fuels into fuel gas. These studies are conducted by looking at opportunities to improve the energy efficiency of the gasification process of biomass.
\end{abstract}

\section{Introduction}

Electricity and thermal energy are two of the primary energy carriers needed in municipal economy. Traditionally these energy carriers are made from fossil fuels. These fuels as non-renewable are going to exhaust. At the moment, the emphasis is placed on increasing the use of renewable energy resources. In addition to wind and solar energy in Poland we have a significant amount of available biomass. This fuel can partly replace fossil fuels. Technology characterized by high fuel use efficiency are cogeneration systems. Using biomass as fuel in them we get high-technology based on renewable energy sources. One possible solution is to use a gas-powered internal combustion engine cogeneration module from the gasification of biomass. Still new concepts are being developed of installation of gasification of biomass [1]. High-efficiency gasproducing energy solutions are still being looked for with a low content of tar. The gasification process is endothermic and requires the delivery of thermal energy. The source of this energy is the partial combustion of the fuel. Successive stages of gasification of fuel are drying, pyrolysis, partial combustion and gasification of carbon residue. For the purpose of drying and pyrolysis waste heat can be used which will increase the energy efficiency of the conversion process of solid fuel into gas $[1,2]$. The drying process takes place at a little more than $100^{\circ} \mathrm{C}$. In order to determine the level of the temperature necessary for the process of the partial thermal decomposition, thermogravimetric research of fuels can be used. They will allow to specify for which temperatures and to what extend solid fuel will undergo degassing.

In the case of biomass, which has a high content of volatile substances, pyrolysis process allows to convert, in considerable part, to transform this solid fuel into gas fuel.

\section{Thermogravimetrics}

Thermogravimetrics is one of the methods of thermal analysis. It is a method of measuring the change in mass of the analyzed sample of the substance, resulting from the impact of the temperature value on this sample in controlled atmosphere (oxidizing - oxygen, air or neutral - nitrogen, argon). Mass variation is due to the physical and chemical changes occurring as a result of the environmental impact on a sample of the appropriate temperature and atmosphere. Thermogravimetric analysis is indicated as TGA. Due to the versatility of the thermogravimetric analysis and the ability to use it for a variety of materials, it is used in many fields of science and technology. $[3,4]$

In the case of studies of fuels in the neutral atmosphere (simulating the process of pyrolysis) mass variation is due to the moisture evaporation and the thermal decomposition of a solid substance as a result of which gases and condensing compounds arise. TGA analysis, by which thermogravimetric curves are obtained, let us estimate the degree of degassing of sample of function of changes of temperature process and the course of process over time.

Unfortunately, commercially available apparatus for thermogravimetric analysis is expensive. Purchase of a thermobalance is the cost of PLN 200 000. An even greater cost is associated with the analyzer of gas composition resulting from the thermal decompositionspectrometer. Due to the high price of devices an attempt was undertaken to build a thermogravimetric snap to a precision scale for the purpose of equipment of the Laboratory of Fuels and Energy Conversion of Institute

a Corresponding author: robert.wroblewski@put.poznan.pl 
of Electrical Power Engineering, Poznan University of Technology.

The project aims to minimize the construction costs of the system. The premise is to allow the stand to perform a thermogravimetric analysis of fuels for laboratory and classroom purposes. The further part of this research paper presents the concept, design and construction of the device to thermogravimetric measurements and the results of tests carried out on two types of solid fuels (pellets and energy willow wood chips).

\section{Description of the test stand}

A typical commercial thermobalance is characterized by the following parameters described in table 1

Table 1. The selected technical data for examples of the commercial thermobalances $[9,10]$

\begin{tabular}{|c|c|c|c|c|}
\hline type TG & $\begin{array}{c}\text { Maximum } \\
\text { temperature }\end{array}$ & $\begin{array}{c}\text { Range of } \\
\text { weigh }\end{array}$ & $\begin{array}{c}\text { Resolution } \\
\text { of weigh }\end{array}$ & $\begin{array}{c}\text { Volume of } \\
\text { crucible }\end{array}$ \\
\hline $\begin{array}{c}{ }^{\circ} \mathrm{C} \\
\text { TG 209 }\end{array}$ & 1100 & 2000 & 0,0001 & 0,35 \\
\hline $\begin{array}{c}\text { FG Libra } 209 \\
\text { F3 Tarsus }\end{array}$ & 1000 & 2000 & 0,0001 & 0,35 \\
\hline $\begin{array}{c}\text { TGA 2 } \\
\text { XP1 }\end{array}$ & 1100 & 1000 & 0,001 & $0,02-0,9$ \\
\hline $\begin{array}{c}\text { TGA 2 } \\
\text { XP1U }\end{array}$ & 1100 & 1000 & 0,0001 & $0,02-0,9$ \\
\hline $\begin{array}{c}\text { TGA 2 } \\
\text { XP5 }\end{array}$ & 1100 & 5000 & 0,001 & $0,02-0,9$ \\
\hline $\begin{array}{c}\text { TGA 2 } \\
\text { XP5U }\end{array}$ & 1100 & 5000 & 0,0001 & $0,02-0,9$ \\
\hline
\end{tabular}

Weight in commercial thermogravimeters is characterized by a high resolution which is one of the reasons for the high price of the device. In addition, low maximum mass of a sample and especially the low volume of typical evaporating dishes may cause difficulty in placing a sample of the fuel in the raw form (e.g. wood in the form of wood chips) to such attempts wood chips should be additionally crushed.

Laboratory of the Institute of Electric Power is equipped in precise scale of range of $320 \mathrm{~g}$ and a resolution of $1 \mathrm{mg}$ and analytical scale AS 60.3 of range $60 \mathrm{~g}$ and a resolution of $0,1 \mathrm{mg}$. In order to carry out the analysis of thermogravimetric fuels the concept to build a thermogravimetric snap-in to already owned scales. A schema of designed measuring system is shown in Figure 1.

Measurement system, whose schema is shown in Figure 1 is situated in the Laboratory of Fuel and Energy Conversion of Institute of Electrical Power Engineering of Poznan University of Technology.

The various elements of the system are: 1 -the nitrogen bottle, 2-pressure reducer for nitrogen, 3-rotameter with a valve to regulate the flow of gas, 4-thermogravimeter body, 5-the crucible with the sample on it, 6-analytical balance, 7-control system with integrated power switch and two temperature regulators type PID, T1, T2temperature sensors-thermocouples type K.

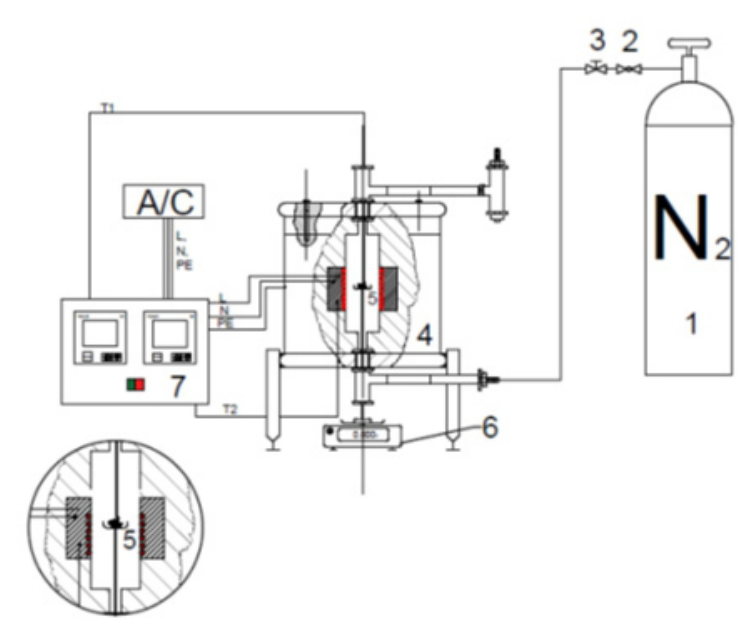

Figure 1. The schema of thermobalance.

In addition to the previously described scale, the key element of thermobalance is the heating chamber. The basis for the construction of the heating chamber is ceramic muffle $0.4-\mathrm{MFO}$ - interior size $\varnothing 70 \times 120 \mathrm{~mm}$ with heating element $1100 \mathrm{~W}(230 \mathrm{~V})$ (Figure 2).

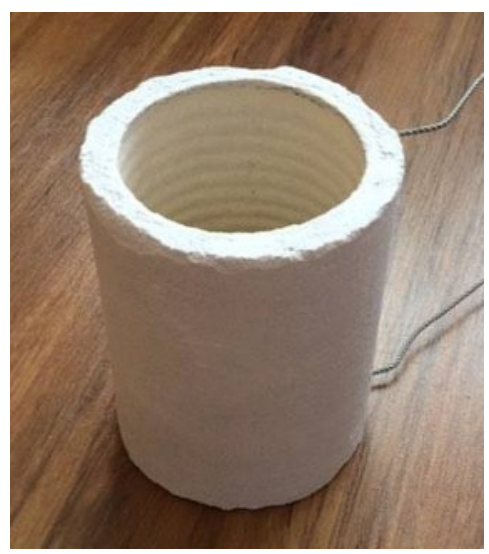

Figure 2. Ceramic muffle

Nominal temperature of the heating muffle is $1100^{\circ} \mathrm{C}$ (maximum $1200^{\circ} \mathrm{C}$ ). The supporting structure of heating muffle is made from ceramic mat with a thickness of $12 \mathrm{~mm}$ soaked with IZO 12 hardener. The whole has been additionally sealed with a rock wool and covered with galvanized sheet (Figure $3 b$ ). For temperature measurement K-type thermocouples were used. Thermocouple $\mathrm{T} 1$ is placed directly above the test sample. T2 thermocouple is placed in the ceramic material covering heating element.

An evaporating dish to a scale is made of bottom board stainless steel with a diameter of $5 / 4$ and $6 / 4$ inch and stainless steel pipe 6 and $8 \mathrm{~mm}$ (Figure 3a).At the bottom of the snap-in a bushing was made to the cantilever of the crucible and delivery of nitrogen to the heating chamber. Nitrogen is used to displace oxygen from the heating chamber while simulating the process of pyrolysis. In the upper part of the casing of the snap-in, a bushing for sheathed thermocouple and process gas outlet were made. Conduits are made of brass hydraulic components $1 / 2$ inch. To control temperature the PID type controller is used. 
a)

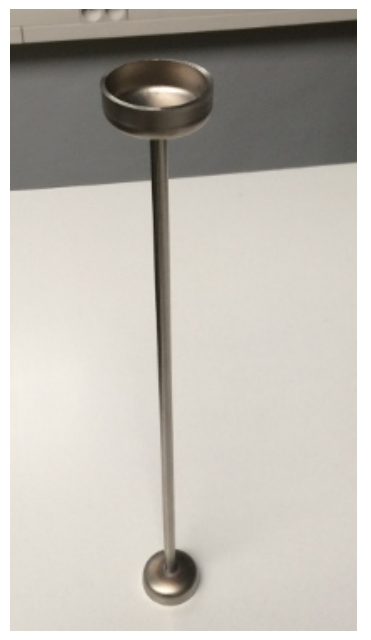

b)

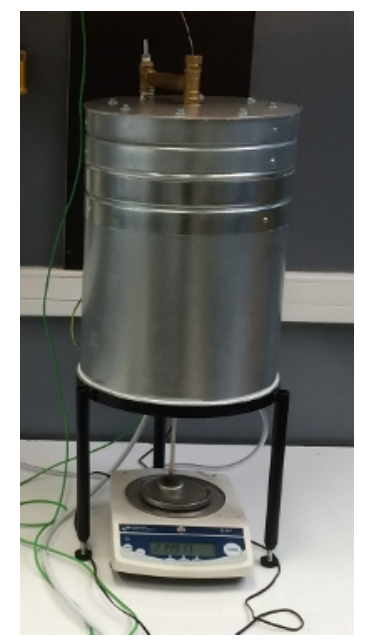

Figure 3. Thermobalance evaporating dish (a) and thermobalance(b).

\section{Test results}

After placing the sample in the crucible of the heating chamber it is washed out with inert gas $\left(\mathrm{N}_{2}\right)$ in order to remove the oxygen. The presence of oxygen in the air would cause that, instead of the pyrolysis process, combustion process would occur. Then the process of heating of the sample begins to the assumed temperature controlled by PID-type controller. In the course of the study the change of the mass of the sample is recorded and the temperature value.

The subject of the study were samples of fuel in the form of sawdust pellets from the sawmill and wood chips from energy willow. The results of the technical analysis of these fuels are presented in table 2. These are the average values of the three measurements. Thermobalance tests were carried out by heating the weighed sample of fuel to the required temperature by keeping on this temperature for some period of time. The following thresholds of temperature were adopted: $300{ }^{\circ} \mathrm{C}, 350{ }^{\circ} \mathrm{C}, 400{ }^{\circ} \mathrm{C}$ and $500{ }^{\circ} \mathrm{C}$. In addition, the study was carried out with a multistep raising of the temperature of the same sample of fuel. In the first step the temperature was raised to $200{ }^{\circ} \mathrm{C}$ and then gradually by another $50^{\circ} \mathrm{C}$. In the course of the research the change of temperature and the mass of the sample were recorded. The results of the research in the form of thermogravimetric curves are shown in figures 4-14.

Both tested fuels are characterized by a small ash content. Energy willow has a slightly higher moisture content and lower heating value.

Table 2. Characteristics of selected parameters pellets and willow chips

\begin{tabular}{|c|c|c|c|}
\hline & Ash & Moisture & Calorific value \\
\cline { 2 - 4 } & {$[\%]$} & {$[\%]$} & {$[\mathrm{kJ} / \mathrm{kg}]$} \\
\hline pellet & 0.85 & 6.3 & 18347 \\
\hline willow & 0.75 & 8.5 & 17476 \\
\hline
\end{tabular}

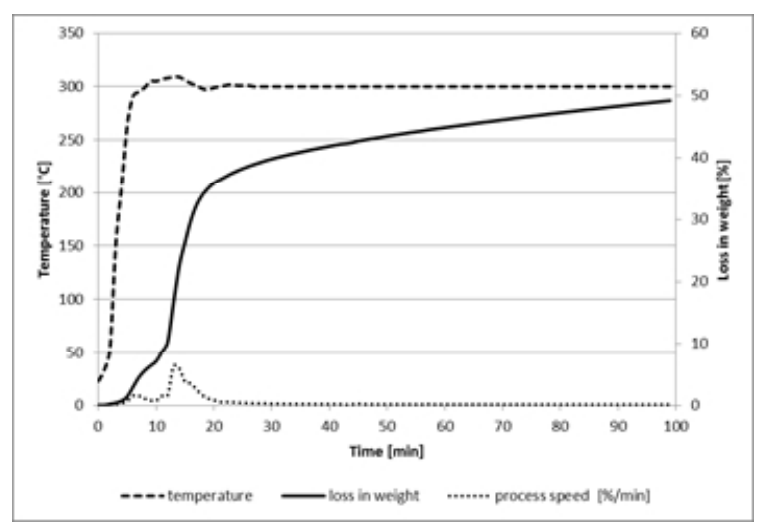

Figure 4. Thermogravimetric curves for wood pellets in real time for temperature $300^{\circ} \mathrm{C}$.

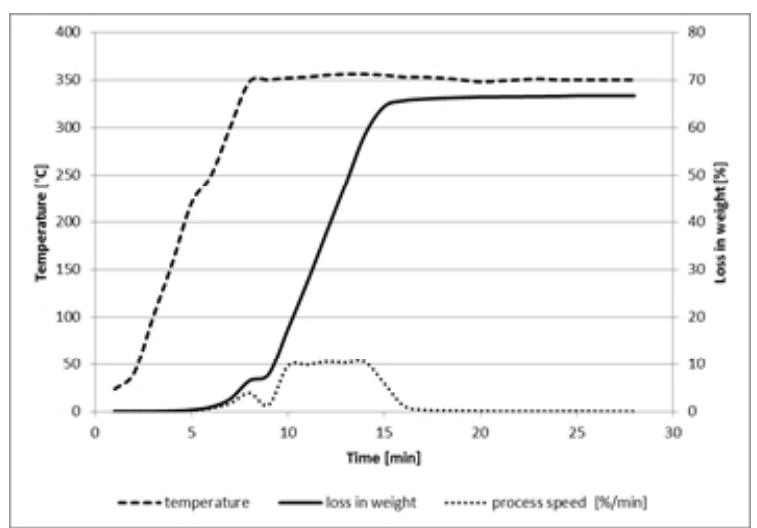

Figure 5. Thermogravimetric curves for wood pellets in real time for temperature $350^{\circ} \mathrm{C}$

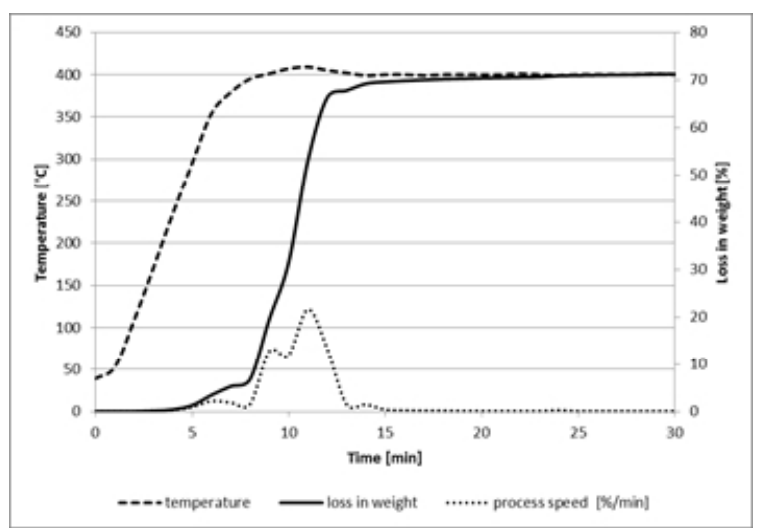

Figure 6. Thermogravimetric curves for wood pellets in real time for temperature $400^{\circ} \mathrm{C}$.

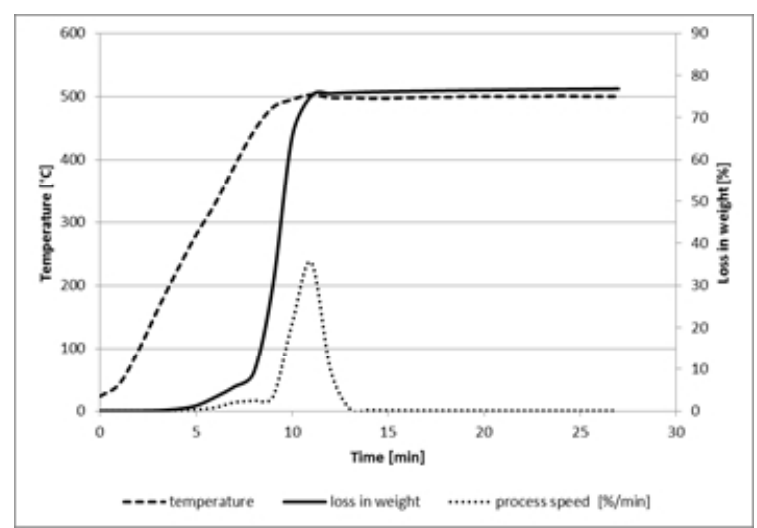

Figure 7. Thermogravimetric curves for wood pellets in real time for temperature $500^{\circ} \mathrm{C}$. 


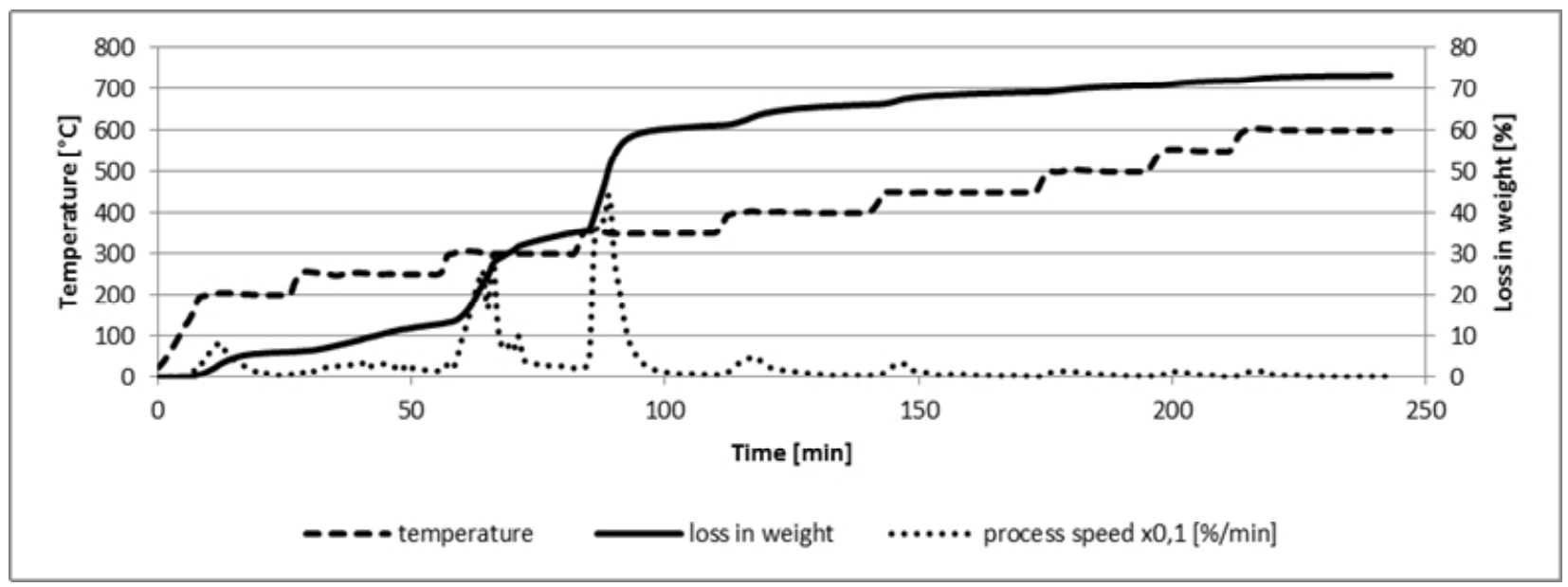

Figure 8. Thermogravimetric curves for wood pellets in real time for a multi-step heating

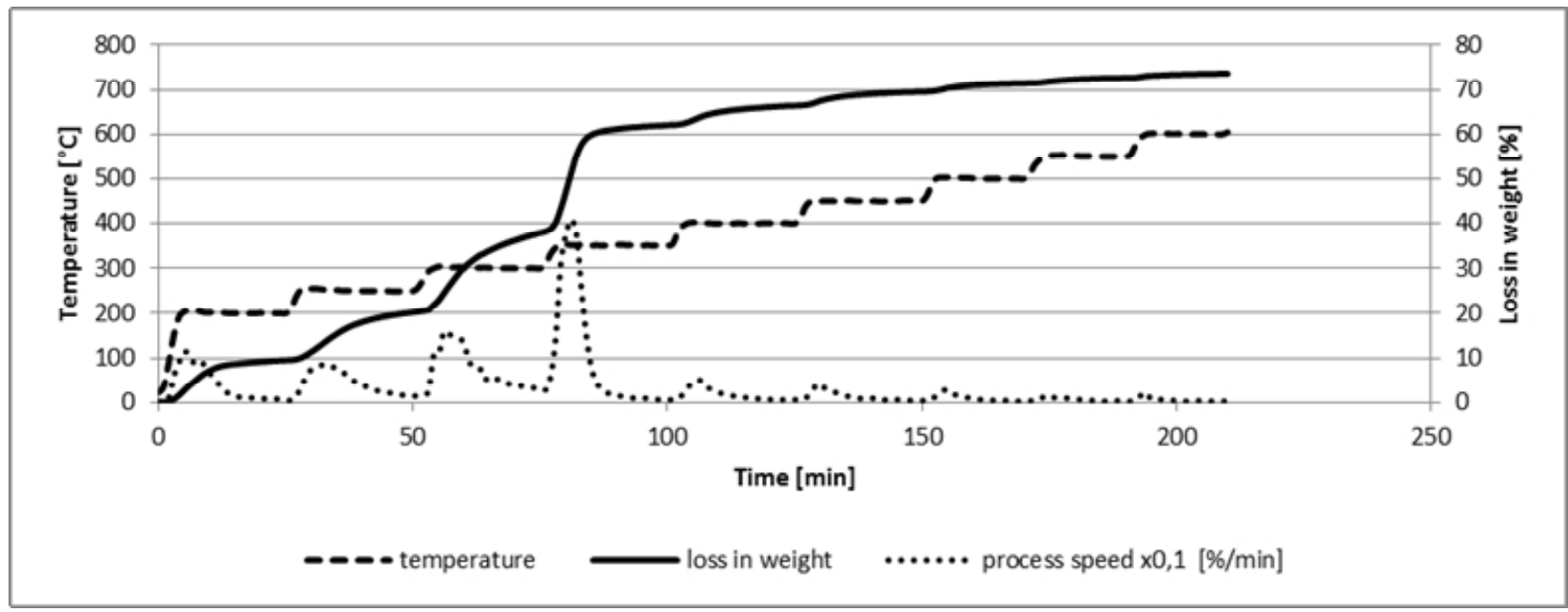

Figure 9. Thermogravimetric curves for willow wood chips in real time for a multi-step heating

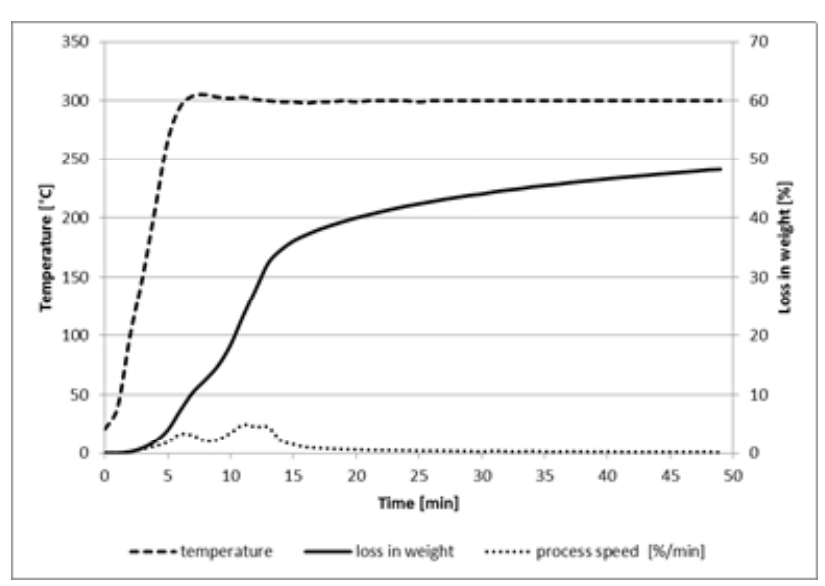

Figure 10. Thermogravimetric curves for Willow wood chips in real time $300^{\circ} \mathrm{C}$.

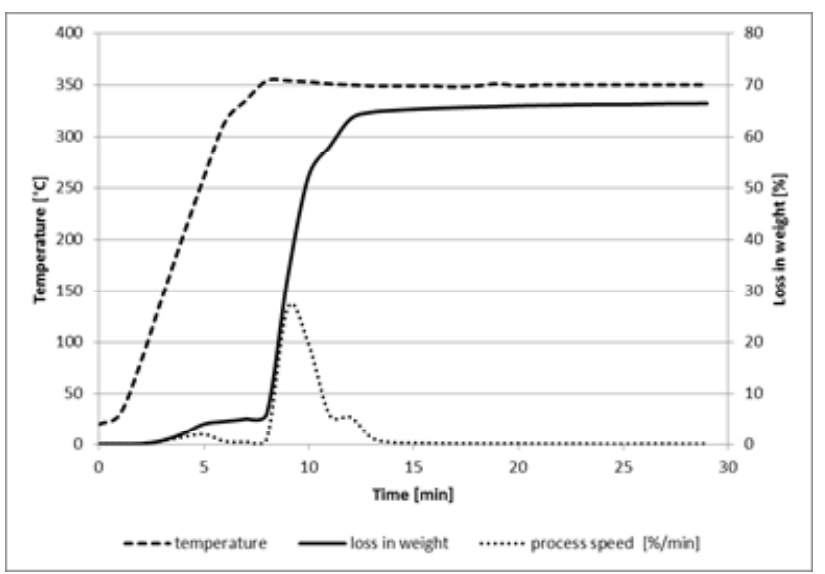

Figure 11. Thermogravimetric curves for Willow wood chips in real time $350^{\circ} \mathrm{C}$. 


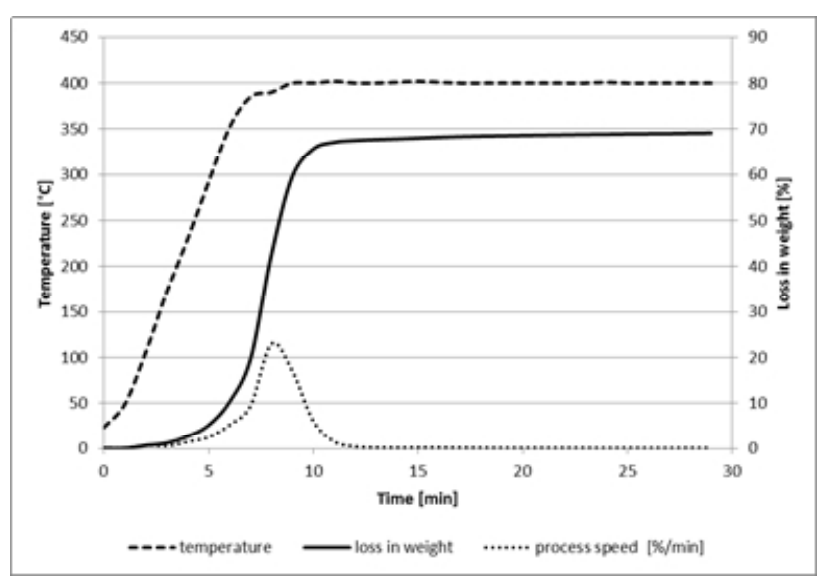

Figure 12. Thermogravimetric curves for Willow wood chips in real time $400^{\circ} \mathrm{C}$.

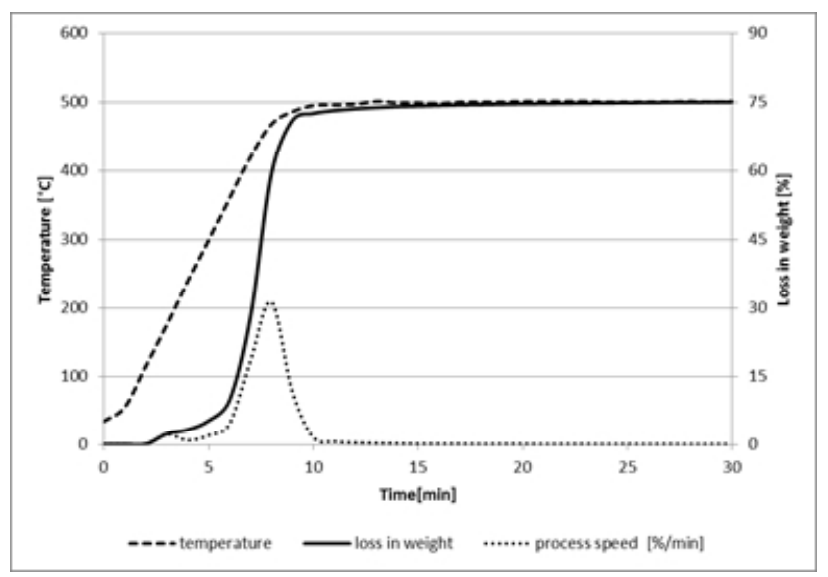

Figure 13. Thermogravimetric curves for Willow wood chips in real time $500^{\circ} \mathrm{C}$.

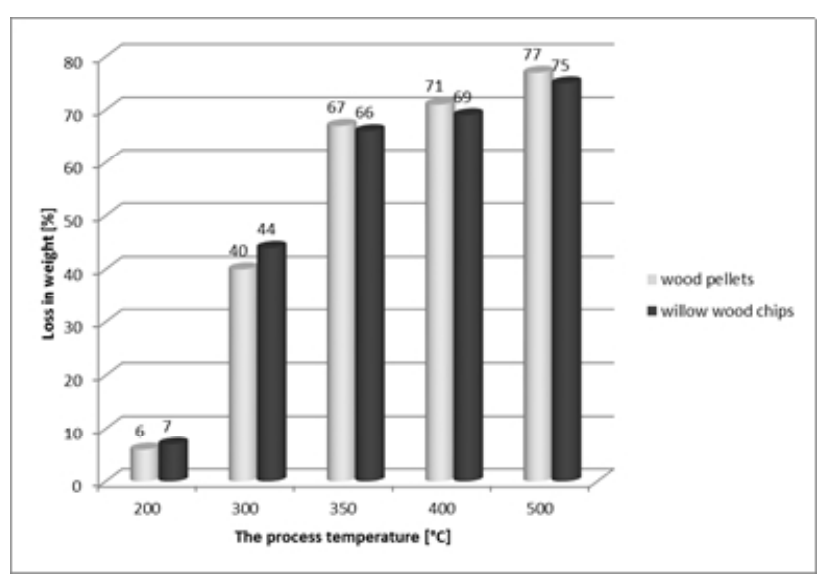

Figure 14. The dependency of the conversion degree of tested fuels from the process temperature

\section{The analysis of the obtained results}

As is evident from the thermogravimetric curves (fig. 4) the heating chamber has reached the preset temperature after about $5 \mathrm{~min}$. After about 10 minutes the process of heating up the sample and its drying ended. For the next 10 min lasted an intense pyrolysis to achieve $35 \%$ weight loss. Then the process of thermal decomposition was crawling with definitely less intensity. The next charts (Figures 5-7) show that increasing temperature of the process causes minor lengthening of the waiting time to achieve the preset temperature while reducing time when intensive pyrolysis occurs. In these cases, the process of further slow loss of mass is far less intense or virtually unnoticeable. Figure 8 shows the thermogravimetric curves for the gradual raising of temperature by $50{ }^{\circ} \mathrm{C}$ starting from $200{ }^{\circ} \mathrm{C}$. In this case, we can notice at which temperature ranges the pyrolysis process is the most intense. The greatest weight losses were reported for $250-350{ }^{\circ} \mathrm{C}$ temperature range. Similarly, in a study came out with the energy Willow shavings (Figure 9). Here also the biggest weight loss that is the greatest intensity of pyrolysis has been reported for temperatures in the range of $250-350{ }^{\circ} \mathrm{C}$. Similarly, as in the case of the pellet process, looks pyrolysis of wood chips at a temperature of $300^{\circ} \mathrm{C}$ (Figure 10). In this case, the process of intense pyrolysis lasted for a shorter time. After a period of intensive weight loss pyrolysis continued but definitely less intense. In other cases (Figure 11-13) increase in temperature causes a shortening of the time of thermal decomposition. Pyrolysis of willow wood chips carried out in a little shorter time than for the corresponding temperature the pyrolysis of wood pellets. Figure 14 shows the dependence of the degree of conversion of solid fuel into gas depending on the temperature of the process. In case of raising the temperature of fuel to $300{ }^{\circ} \mathrm{C}$ about $40 \%$ of the fuel conversion of solid fuel into gas was obtained. Similarly for temperatures of $350{ }^{\circ} \mathrm{C} 66 \%$ conversion is obtained. For subsequent temperature thresholds, these growths are smaller. For $400{ }^{\circ} \mathrm{C} 70 \%$ is obtained and up to $500{ }^{\circ} \mathrm{C}$ approx. $77 \%$ degassing of fuel.

\section{Summary}

Constructed apparatus allows to study thermal decomposition of solid fuels and obtained thermogravimetric curves are similar to those that can be performed on commercial thermobalances [5-9]. The advantage of the device is definitely lower price than of commercial solutions (approx. 100 times). Preferred option seems to be also a larger size of a chamber and evaporating dish allowing the analysis of larger samples of fuel. Commercial solutions have a cooling system that allows for relatively fast exit of the heating chamber and enabling the implementation of the next measurement. Therefore the cooling system would be a welcome improvement in the next version of this type of device. A welcome improvement would be to use temperature regulator with the possibility of registration data and control from your PC. Despite these imperfections it can be considered that building of such a device meets the goal of thermogravimetric testing of fuels.

On the basis of an analysis of the results of thermogravimetric research of sawdust pellets and energy willow wood chips, it can be concluded that for the tested biofuels the most intensive process took place in temperature range around $300-400{ }^{\circ} \mathrm{C}$. As a result of pyrolysis for this temperature range for tested biomass, a high conversion level of solid fuel into gas was obtained. This allows to draw the conclusion, at least in significant part, that the conversion of fuel towards providing the necessary heat for that endothermic process coming from hot waste gases is possible. Usually the heat of this type of gas is used for heating purposes. The use 
of them in wood gas generator would let reduce the amount of heat produced in the combustion of the fuel components. In small wood gas generator systems for combustion air is provided. This causes the appearance of ballast in the form of nitrogen in producer gas. Partial combustion and nitrogen from the air reduce the energy value of arising gas fuel. Application of waste heat to the process of initial pyrolysis will help to limit the amount of heat generated in combustion process. This will limit the amount of air needed. As a result, it will allow to increase the efficiency of the gasification process of solid fuel and improvement of the quality of this gas. To confirm this thesis, however, you should carry out more trials of this type as well as broaden the scope of tested biofuels.

\section{References}

1. H. A. M. Knoef, Handbook Biomass Gasification Second Edition, BTG (2012)

2. R. Wróblewski, Koncepcja małego układu kogeneracyjnego zintegrowanego ze zgazowaniem biomasy, Polityka Energetyczna, 17, 159-170 (2014)

3. M. Szumera, Charakterystyka wybranych metod termicznych. Cz. 1, LAB Laboratoria, Aparatura, Badania, 6, 28-34 (2012).

4. D. Schultze, Termiczna analiza różnicowa, PWN (1974)

5. H. Liu, K. Han, M. Liu, S. Niu, C. Lu, Energ. Source Part A, 37, 22 (2015)

6. C. Deyong, L. Shaohua, J. Jia, Z. Rui; Thermogravimetric Analysis of Pyrolysis Characteristics of Biomass; World Automation Congress (WAC), 2012

7. W. Jin, K.a Singh, J. Zondlo, Agriculture, 3, 1, 12-32 (2013)

8. M. Carrier, A. Loppinet-Serani, D. Denux, J.-M. Lasnier, F. Ham-Pichavant, F.Cansell, C. Aymonier, Biomass and Bioenergy, 35 (2011)

9. L. Gašparovič, Z. Koreňová, L. Jelemenský1; Kinetic study of wood chips decomposition by TGA; 36th International Conference of SSCHE May 2529, 2009,

10. http://www.mt.com

11. http://www.netzsch-thermal-analysis.com 